\title{
IDŐJÁRÁS
}

Quarterly Journal of the Hungarian Meteorological Service

Vol. 125, No. 2, April-June, 2021, pp. 255-269

\section{Assessment of agrometeorological indices over Southeast Europe in the context of climate change (1961-2018)}

\author{
Hristo Chervenkov* and Kiril Slavov \\ National Institute of Meteorology and Hydrology \\ 66, Tsarigradsko Shose blvd Sofia 1784, Bulgaria \\ *Corresponding author E-mail: hristo.tchervenkov@meteo.bg
}

(Manuscript received in final form July 8, 2020)

\begin{abstract}
The regional response over Southeast (SE) Europe to the climate warming in global and continental scales has been confirmed to have essential impact on the agriculture and forestry since the middle of twentieth century. Normal variations in weather throughout a growing season cause variations in harvest and, generally, the impact could be large in terms of production amounts and economic returns. Agriculture is sensitive to the changes in weather and climate, and the occurrence of extreme events threaten the agricultural systems. Forests are particularly sensitive to climate change, because the long life-span of trees does not allow for rapid adaptation to environmental changes. This study provides an overview of the spatial patterns and the long-term temporal evolution of the following agrometeorological indices: growing season length, accumulated active temperatures and biologically effective degree days. Hence the focus is on the Growing season length, its start and end dates are analyzed separately. All indices are computed from the daily mean temperatures which, in turn, are derived from the output of the MESCAN-SURFEX system analysis of the collaborative initiative UERRA. The geographical domain of interest is Southeast Europe, and the assessment is performed at a very high spatial resolution on annual basis for the period 1961-2018. We find strong evidences of essential increase in the considered indices which dominates spatially over the low-elevated areas of the domain and is statistically significant at $5 \%$ level. Key message is also the revealed asymmetry of the increase in the most relevant index, the growing season length: its total lengthening is linked more to the shifting to earlier date of the start, rather than to its later cessation.
\end{abstract}

Key-words: UERRA MESCAN-SURFEX, daily mean temperature, agrometeorological indices, Southeast Europe, regional warming 


\section{Introduction}

According to the high-level synthesis report of the United Nations, titled 'United In Science' (https://public.wmo.int/en/resources/unitedinscience), the climate change is the defining challenge of our time. The globally averaged surface temperature of the Earth increased $0.85{ }^{\circ} \mathrm{C}$ over the 1880 to 2012 period (Janković et al., 2019). The climate change will exert influence on the ecosystems, on all branches of the international economy, and on the quality of life. That is why an operation plan for adaptation to climate changes has to be based on scientifically well-grounded assessments, giving an account of regional features in the climate changes and their consequences.

Food security is a fundamental precondition for human well-being, and the agricultural and food sector is of major economic importance. Agriculture is arguably the sector most dependent on climate. Crops and livestock are directly impacted by adverse local weather and climate. Indirectly, food production is affected by climate-driven fluctuations in water resources as well as in the processing, transport, and storage of agricultural products.

Associated with climate change there are several factors affecting forest ecosystems, which can act independently or in combination. As evidenced in many recent publications, the changes in climate have direct and indirect impact on biotic (frequency and consequences of pest and disease outbreaks) and abiotic (changes in occurrence and intensity of severe weather episodes) disturbances with strong implications for forest ecosystems. The comprehensive study of Lindner et al. (2010) compiles and summarizes the existing knowledge about observed and projected impacts of climate change on forests in Europe. Key message in this study is that the negative impacts of the climate change are very likely to outweigh positive trends (connected mainly with the increasing atmospheric $\mathrm{CO}_{2}$ concentration and higher temperatures) in the southern and eastern parts of Europe. The impact of the climate change on the population of widespread conifer species with high economic and ecological value like silver fir and Norway spruce is considered in the local studies for Romania (Mihai G, et al., 2018, 2020). The studies outline the high adaptive genetic variation of the Norway spruce in Southeast (SE) Europe and the resilience of the silver fir to climate change in the region.

Temperature is one of the major environment factors affecting the growth, development, and yields of crops, especially the rate of development. On one hand, crops have basic requirement for temperature to complete a specific phenophase or the whole life cycle. On the other hand, extremely high and low temperatures can have detrimental effects on crop growth, development, and yield, particularly at critical phenophases such as anthesis Luo (2011).

The study of near past climate provides an essential baseline, from which changes in the contemporary and future climate can be understood and contextualized. Past and future climate norms, documenting of climate change 
are required to support transformational decisions, such as breeding new crop varieties, investments in irrigation, or relocation of production areas.

The global warming effects and the associated regional climatic changes over Central and Southeast (SE) Europe have been widely documented in the last decades based on in situ measurements (Alexandrov et al.,2004; Bartholy and Pongrácz, 2006; Pongrácz et al., 2009a, 2009b; Croitoru et al., 2012), assimilated surface observations (Birsan et al., 2014; Chervenkov and Slavov, 2019a; Cheval et al., 2014; Lakatos et al., 2013a, 2013b), reanalyses (Malcheva et al., 2016; Spinoni et al., 2015), global (Sillmann et al., 2013), Chervenkov and Slavov (2020a)) and regional climate models (Belda et al., 2015; Gadzhev et al., 2018; Pieczka et al., 2019; Spiridonov and Valcheva, 2019). Most of these studies are focused on the second half of the 20th and the first decade of the 21st century, clearly evidencing that, similarly to the global and continental trends, the regional temperature got warmer during the period. Investigations of the changes in annual variation patterns under current climatic conditions across SE Europe aim to increase the current knowledge of recent climate changes in this region, and also to provide the baseline for the foregoing assessments of possible responses of the regional climate to global warming (Birsan et al., 2014).

Main aim of the present study is to analyze the spatial patterns and the temporal evolution of the near past and present thermal conditions over SE Europe from agrometeorological (AM) point of view using up-to-date data sources. These conditions are quantified by a set of AM indices with focus on the growing season length (GSL) index computed on annual basis from the daily mean temperatures. The daily mean temperatures are, in turn, derived from the output of the MESCAN-SURFEX model in the frames of the UERRA project (Unden, 2018) for the full 58-year-long time span of the data set (1961-2018) and in very high grid spacing of $0.05^{\circ} \times 0.05^{\circ}$.

The article is structured as follows. The used data and the considered indices are described in Section 1. The core of the article is Section 2, containing 3 subsections and performed calculations and obtained results. The concluding remarks are in Section 3.

\section{Data and methods}

\subsection{Concise remarks on UERRA and MESCAN-SURFEX}

The objective of the project-driven collaborative initiative UERRA (Uncertainties in Ensembles of Regional Reanalyses (RRA); www.uerra.eu ) is to produce ensembles of European RRA of essential climate variables for several decades and to estimate the associated uncertainties in the data sets (Ridal et al., 2018; Unden, 2018). It also includes recovery of historical (last 
century) data and creation of user friendly data services. Within UERRA, three different numerical weather prediction (NWP) models have been employed to generate European RRA and subsequent surface reanalysis products.

The MESCAN-SURFEX system analysis uses the 2D-analysis system MESCAN (Soci et al., 2016) and the land surface platform SURFEX (Bazile et al., 2017) to generate a coherent surface and soil analysis. The UERRA-NWP HARMONIE-ALADIN at $11 \mathrm{~km}$ grid spacing is used as a starting point to further downscaling. Besides the other parameters, MESCAN-SURFEX produces air temperature at $2 \mathrm{~m}$ above the surface in 6-hour temporal resolution, i.e., at 00, 06, 12, and 18 UTC for the period 1961-2018. Based on the availability of this data, the daily minimum, mean, and maximum temperatures, noted henceforth $\mathrm{tm}$, $t g$, and $t x$ correspondingly, are derived in a regular $0.05^{\circ} \times 0.05^{\circ}$ grid and validated against independent data sets (Chervenkov and Slavov, 2021).

\subsection{Agrometeorological indices}

This study exploits part of the results of the work of Chervenkov and Slavov (2020b), namely the MESCAN-SURFEX derived data for the daily mean temperature, $t g$.

Identification of the effects of mean temperature on crop production under various field/controlled environmental conditions can be used to improve crop models for accurate representation of the impacts of temperature change on crop production at regional level. The impacts of $t g$ on crop production could be quantified by various AM indices (Seemann et al., 1979). Similar to other sector-oriented indicators which have no internationally agreed definitions, the computation of the most of the AM indicators can be performed in different ways, depending on the available data, region of interest, nature and scope of the study (Harding et al., 2015). A certain exception is the GSL, which is standardized in frames of collaborative initiatives like STARDEX, European Climate Assessment \& Dataset (ECA\&D) project (van Engelen et al., 2008), and Expert Team on Climate Change Detection and Indices (ETCCDI, Zhang et al., 2011). According to the unified definition, the GSL is the annual count between the first span of at least 6 days with $t g>5{ }^{\circ} \mathrm{C}$ and first span after July 1 (in Northern Hemisphere) of at least 6 days with $\operatorname{tg}>5^{\circ} \mathrm{C}$. The units of measurement of the GSL are, obviously, days.

It must be emphasized that in some parts of the considered domain, mainly along the coastline of southern Greece, Italy, and Asia Minor, the daily mean temperature is over $5{ }^{\circ} \mathrm{C}$ practically over the whole year. Thus the $G S L$, at least with this threshold temperature, could not be defined in the current way.

In the last decades, significant research has been done in many countries on temperatures critical to plants, and this, along with the aggregate evaluation of 
thermal resources, made a substantially more accurate determination of climatic heat provision to crops possible (Luo, 2011).

The total active air temperature or accumulated active temperature $(A A T)$ index is commonly used AM index mostly for heat assurance characteristics during the growth of some cultivars for example winter wheat (Seemann et al., 1979). AAT is calculated as

$$
A A T=\sum_{i=D O Y B}^{i=D O Y C} \max (\operatorname{tg}(i)-t b, 0)
$$

where $D O Y B$ is the day of year $(D O Y)$ at the start, and $D O Y C$ is the day of year at the end (cessation) of the growing seasons. The threshold temperature, $t b$, is $5{ }^{\circ} \mathrm{C}$ for the cold-tolerant and $10^{\circ} \mathrm{C}$ for the thermophile species (Lakatos et al., 2013b); we use the lower one in the current study. AAT is calculated in units called degree-days, ${ }^{\circ} \mathrm{D}$ (see Janković et al., 2019).

The degree-day method, which expresses numerically the relationship of plant development and growth to atmospheric temperature, was developed in the United States in the first half of the twentieth century. In the degree-day method, the mean diurnal air temperatures above the minimum plant heat requirements are totaled (in essence, this is analogous to the total active temperature method). This method was used in connection with the determination of crop maturation times (Seemann et al., 1979).

The biologically effective degree days $(B E D D)$ index has been specifically targeted to describe grape growth (Gladstones, 1992). The BEDD index is based on a growing degree days measure and is calculated by:

$$
B E D D=\sum_{i=01.04}^{i=30.09} \min \left(\max \left(\operatorname{tg}_{i}-t h, 0\right), t l\right)
$$

where $t h=10^{\circ} \mathrm{C}$ and $t l=9{ }^{\circ} \mathrm{C}$ are the upper and lower threshold temperatures correspondingly. Similarly to the $A A T$, the unit of $B E D D$ is ${ }^{\circ} \mathrm{D}$.

Total active and effective temperatures, subsequently the values of $A A T$ and $B E D D$, as well as ranges for GSL have been established for many crops. These methods of expressing crop heat requirements are widely used for agricultural climate evaluation in the former Soviet Union, Bulgaria, Poland, Romania, and a number of other countries (Seemann et al., 1979), which motivates their selection in the present study.

These indices could be regarded not at least and beyond their AM scope as proxies of the cumulative thermal conditions during the warm period of the year. 


\section{Calculations and results}

\subsection{Verification of the GSL}

The presented definitions on the one hand and the presence of data for the daily mean temperatures on the other give the opportunity for straightforward computation of the considered indices. They are computed with purpose-build procedures by the authors for the whole 58-year-long time span of the input data. First, the obtained results for the GSL are verified against independent data.

The database ClimData (Chervenkov et al., 2019; Chervenkov and Slavov, 2019a, available for free at https://repo.vi-seem.eu/handle/21.15102/VISEEM343.) contains the full set of STARDEX and ETCCDII climate indices (Cis) derived from CARPATCLIM and E-OBS daily temperature and precipitation data. It is intended to serve as convenient and versatile single-point access resource for any user interested in the CIs-based regional climatology. The GSL in the STARDEX CIs-collection is calculated with the original input data for the daily mean temperature and not with approximation using the arithmetic average from the $t n$ and $t x$ as in the ETCCDII-collection. Thus, it is reasonable to expect that it represents better this agrometeorological index. The GSL from STARDEX, based on CARPATCLIM data is compared to the one computed in this study as shown in Fig. 1 .

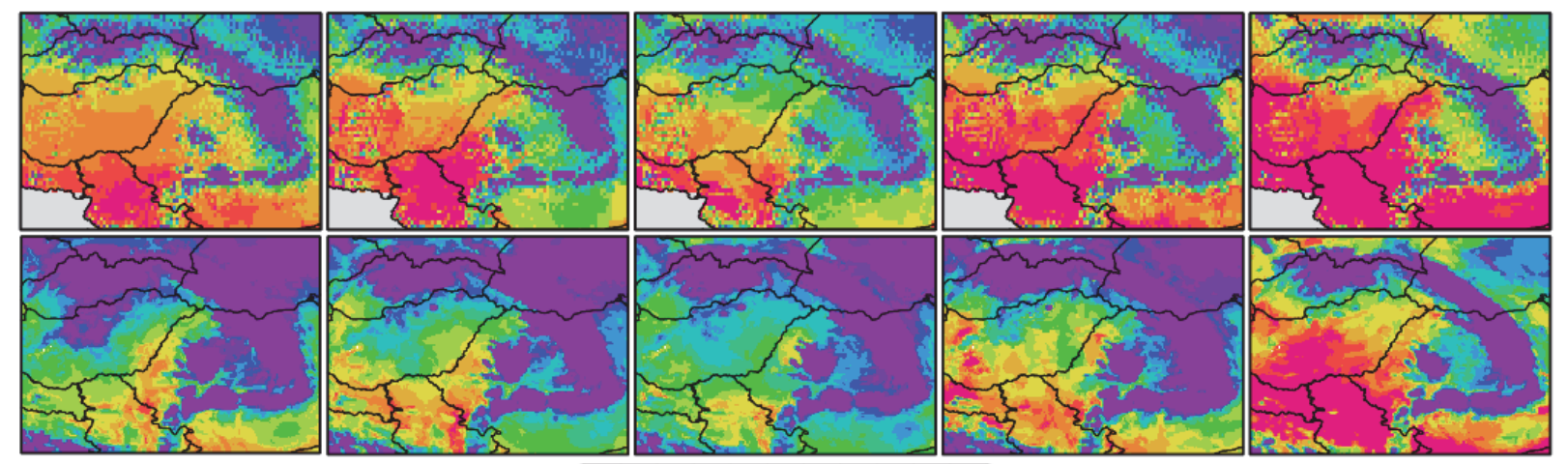

210215220225230235240245250255260265

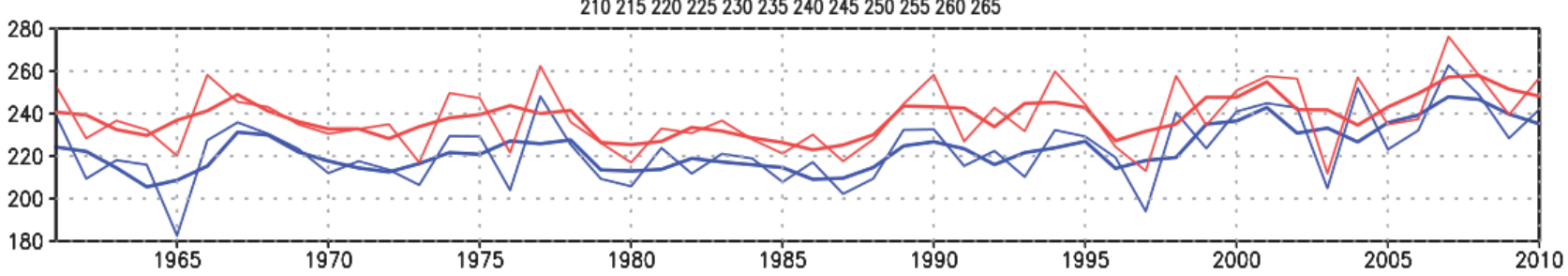

Fig. 1. Upper pane: multiyear means of the GSL (unit: days) for the periods [1961, 1970], [1971, 1980], [1981, 1990], [1991, 2000], and [2001, 2010] in the first, second, third, fourth, and fifth column, correspondingly, from STARDEX/CARPATCLIM (first row) and from UERRA MESCAN-SURFEX derived tg (second row). Lower pane: time series of the area-weighted averages (AA) of the GSL over the CARPATCLIM-domain from STARDEX/CARPATCLIM (red line) and from UERRA MESCAN-SURFEX derived $t g$ (blue line). Fat lines are the running 3-year means. 
Besides the different graphical appearance of the both sets caused by the different grid spacing $\left(0.1^{\circ} \times 0.1^{\circ}\right.$ for STARDEX/CARPATCLIM and $0.05^{\circ} \times 0.05^{\circ}$ in current case), it is most obvious in the superimposition of the spatial patterns, that the GSL is generally underestimated in the present study compared with STARDEX/CARPATCLIM. The evolution of the AAs from both sets is coherent in time with almost constant positive shift of an 15 days of STARDEX/CARPATCLIM calculations in the present study. This fact is a direct consequence of the underestimation of the daily mean temperatures compared to the CARPATCLIM-output (Chervenkov and Slavov, 2020b). As emphasized in Chervenkov and Slavov (2020b), a part of this bias could be attributed to the principally different origin and nature of the considered data sets, which makes it practically unavoidable.

\subsection{Long-term inter-annual changes}

The GSL is certainly the most recognizable AM index and subject of many studies, considering the regional climate (Bartholy and Pongrácz, 2006; Birsan and Dumitrescu, 2014; Chervenkov and Slavov, 2019a). Most of them investigate the GSL solely, whereas little attention is paid on the start date $(D O Y B)$ of the vegetation period as well as to its end (cessation) date, DOYC. Part of the problem lies in the fact that the most standardized software tools for computation of CIs, like RclimDex of ETCCDI, output GSL only and not DOYB/DOYC. In some recent papers, like the study by Szyga-Pluta and Tomczyk (2019), the anomalies are analyzed in the length of the growing season in Poland in the period 1966-2015. The authors reveal statistically significant increase of the GSL on the east coast as well as in the central and southern parts of the country. The changes of the start date over the Carpathian Region in the period 1961-2010 are considered also in Lakatos et al. (2013b) evidencing significant shifting to earlier date. Experimenting with different approaches for calculation of DOYB and DOYC, Mesterházy et al. (2018) reveal that that the $G S L$ in Hungary becomes significantly longer during the 21 st century.

The present study is focusing on the GSL. Hence our main aim is not only to assess the impact of the climate change on the GSL but also to find seasonal shift in the vegetation period, DOYB and DOYC are analyzed together with GSL simultaneously.

First, in order to reveal long-term interannual changes for the considered indices, the spatial patterns of the multiyear means for the first 30-year-long period 1961-1990 are superimposed to the multiyear means for the second 30year-longperiod, 1989-2018 as shown in Fig. 2. 


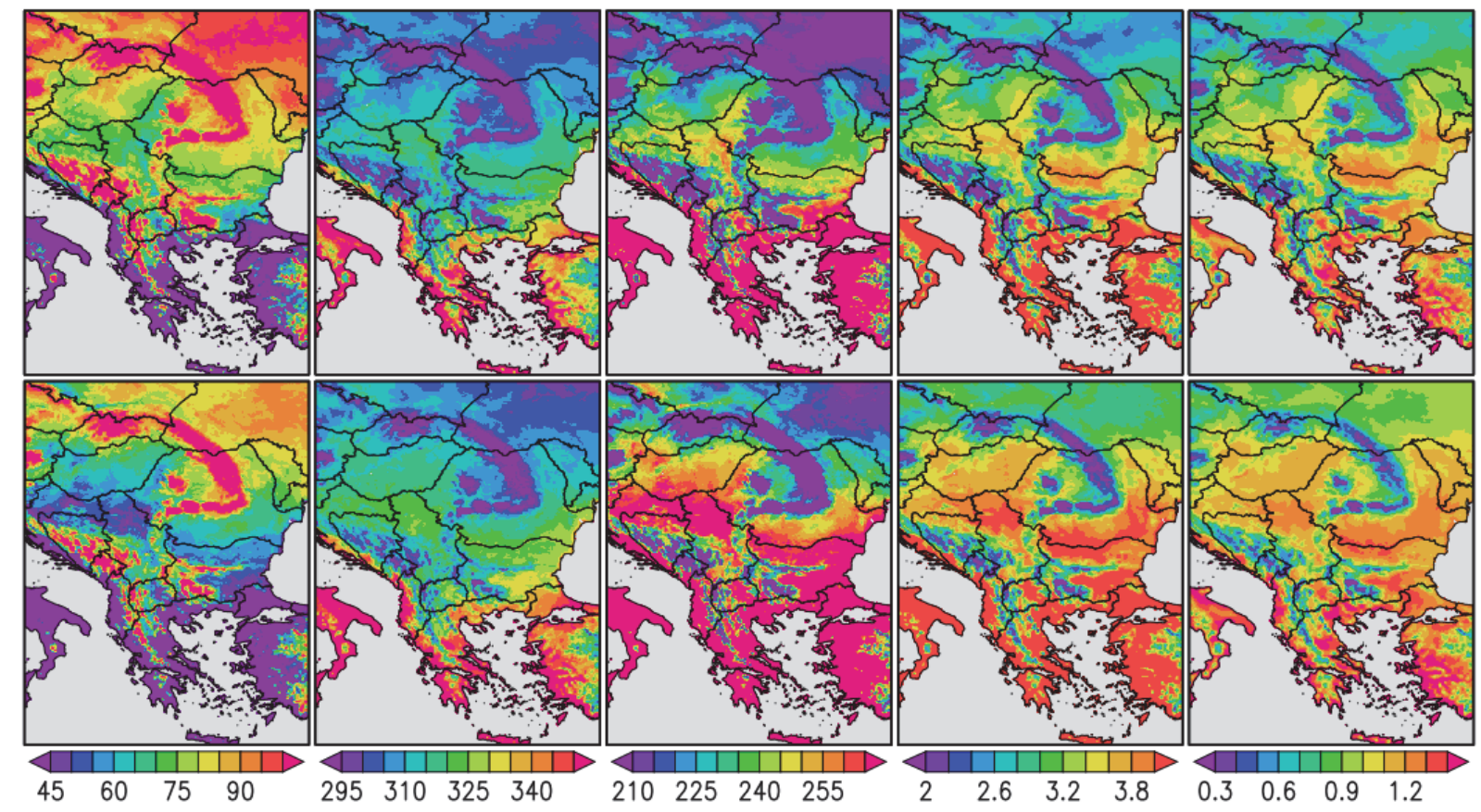

Fig. 2. Multiyear means of $D O Y B, D O Y C$, GSL, $A A T$, and $B E D D$ in in the first, second, third, fourth, and fifth column, correspondingly, for 1961-1990 (first row) and 19892018 (second row). The unit of the GSL are days; $A A T$ and $B E D D$ are presented in $1000^{\circ} \mathrm{D}$ unit.

The spatial patterns of the considered variables are generally consistent in the both time spans. The vertical gradients, especially along the main Carpathian ridge (MCR) are better expressed than the gradients in the latitude. As expected, the analysis shows increase of all variables, except the DOYB which demonstrates opposite tendency.

The interannual shift of the vegetation period could be quantified simply by the middle day of the growing season, $D O Y M=(D O Y B+D O Y C) / 2$, which is independent from the GSL itself. If the DOYM is shifted to an earlier date, independently from the absolute change of the GSL, the vegetation period begins earlier (negative shift); the opposite case, when the detected shift of the DOYM moves towards later dates (positive shift), means later occurrence of the vegetation period.

The logical next step is to assess the absolute difference between the multiyear means of both time spans as well as the relative change in respect to the earlier period. Both of these quantities, which are shown in Fig. 3, could be regarded as measures of the climate change impact on the considered variables. 


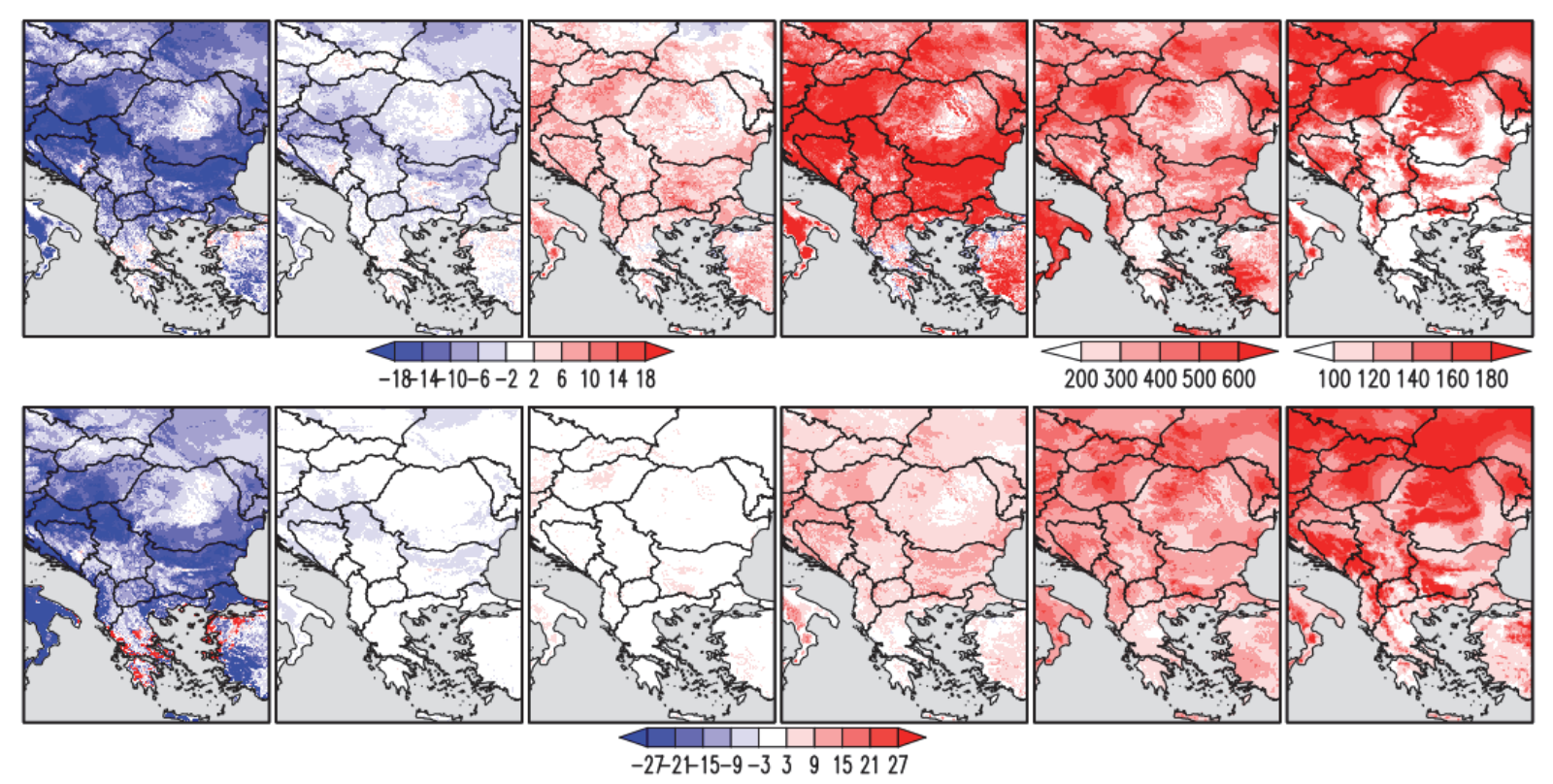

Fig. 3. First row: absolute difference between the multiyear means for 1989-2018 and 1961-1990 for DOYB, DOYM, DOYC, GSL, AAT and BEDD in in the first, second, third, fourth, fifth and sixth column, correspondingly. The units are as in Fig. 2. Second row: relative changes (in \%) in the same order.

The most obvious result from the analysis of Fig. 3 is the substantial increase of DOYC, GSL, AAT, and BEDD over the entire area. The DOYC is shifted towards later dates up to a week, and the $G S L$ is sifted latermore than two weeks over the bigger part of the domain. The increase of the $A A T$, and especially $B E D D$, is spatially more heterogeneous than the increase for the other variables. The vertical gradient of the detected changes is most clearly expressed in relative terms for the $B E D D$. It is worth noting, however, that the latter index has limited applicability in high-elevated areas.

The negative shift of the $D O Y B$ also appears clearly. It is spatially dominating except a few grid cells mostly along the coast lines of Greece and Turkey. In these grid cells, as emphasized before, the vegetation period begins in the first days of the year and small (less than a day) differences results in big relative changes. The decrease of the $D O Y B$ over the flat parts of the domain is generally in the interval of -21 to -9 days which, in absolute terms, is more than the increase of the DOYC over the same places. As a result, the DOYM, i.e., the whole vegetation period, is shifted to earlier dates with generally 2 to 10 days.

The relative share of the negative shift of the DOYB in the total increase of the multiyear mean of the GSL for 1989-2018 relative to 1961-1990 as well as the temporal evolution of the area-weighted over land averages of $D O Y B$, DOYM, DOYC, GSL are shown in Fig. 4. 

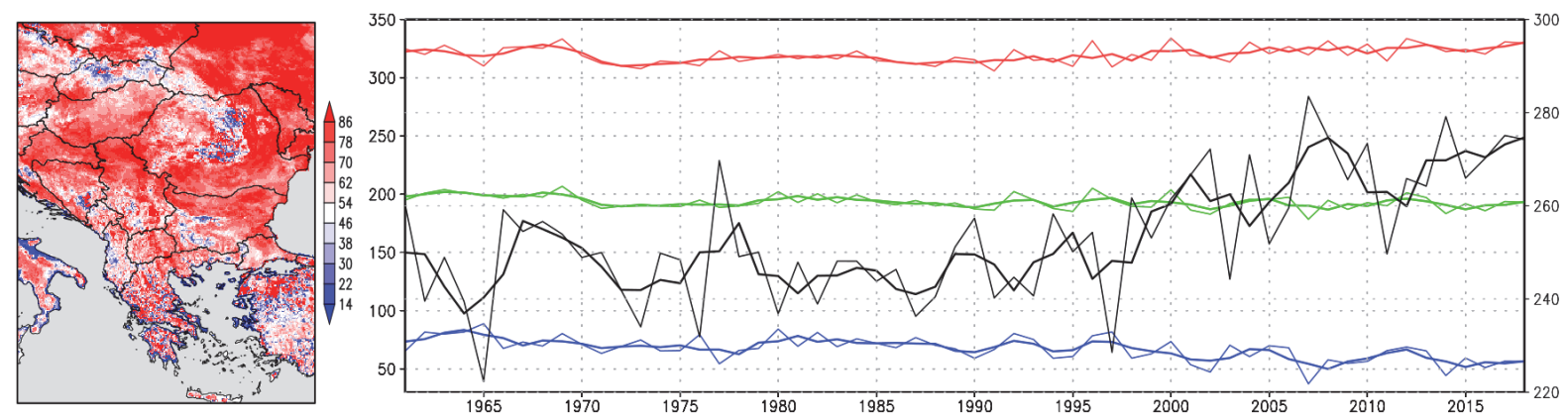

Fig. 4. Left pane: relative share (in \%) of the negative shift of the DOYB in the total increase of the GSL. Right pane: temporal evolution of the DOYB ((blue line), DOYC (red line), DOYM (green line, left ordinate) and GSL (black line, right ordinate, units: days). Fat lines are the running 3-year means.

In agreement with the results from the analysis of Fig. 3, the left pane of Fig. 4 shows that the total increase of the multiyear mean of the GSL for 19892018 relative to 1961-1990 is caused over the flat parts of the domain by more than $70 \%$ from the negative shift of the $D O Y B$. The vertical gradients are clearly distinguishable: over the mountains this share is significantly smaller, suggesting that in these regions the negative shift of the $D O Y B$ has equal, even smaller contribution than that of the positive $D O Y C$-shift in the total increase of the GSL.

The evolution of $D O Y B, D O Y C$, and especially of GSL, as well as in smaller degree of DOYM shows fairly clear tendencies, despite of some colder episodes as, for example, 1965. These episodes are distinguishable also in the lower pane of Fig. 1. The GSL demonstrates significant oscillations from year to year. The uprising tendency, however, especially after 1980-1985, is notable.

The temporal evolution of the AAs of the $A A T$ and $B E D D$ are shown in Fig. 5.

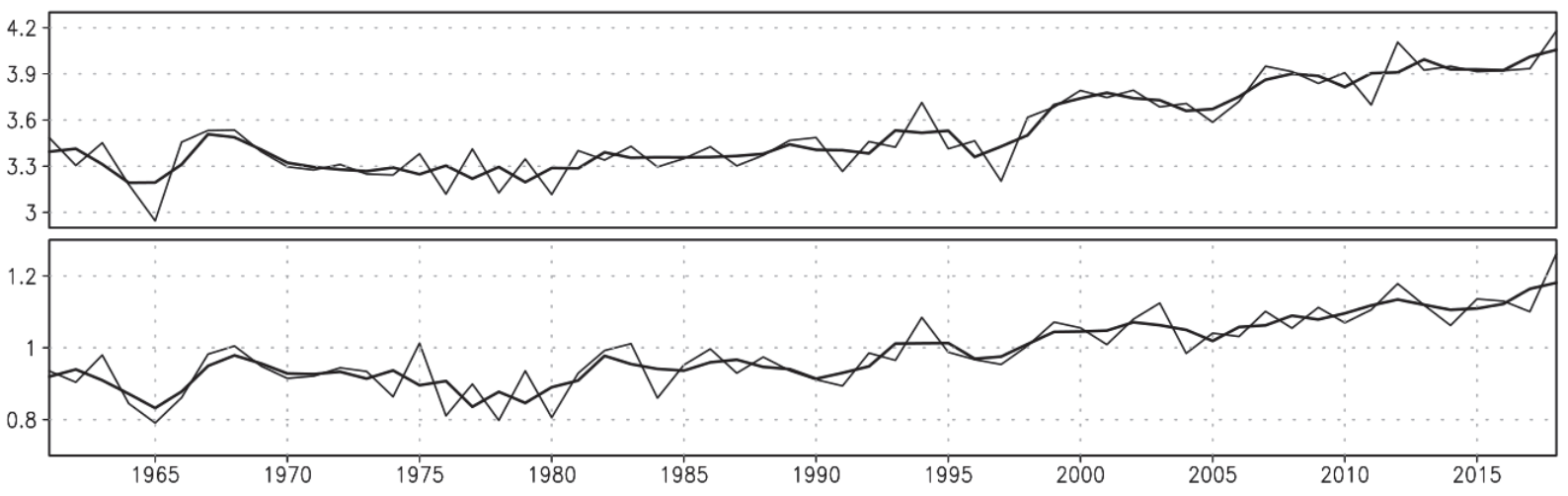

Fig. 5. Temporal evolution of the $A A T$ (upper pane) and $B E D D$ (lower pane) indices. The units are $1000^{\circ} \mathrm{D}$. Fat lines are the running 3 -year means. 
Consistent with the similar results for the GSL, the evolution lines of the $A A T$ and $B E D D$ demonstrate steady increase of these values since the 1980s.

\subsection{Trend analysis}

The importance of assessing trends in climate extremes is often emphasized (e.g., Chervenkov et al., 2019) and, consequently, the trend analysis is an essential part of the most recent studies considering either regional (Bartholy and Pongrácz, 2006; Birsan et al., 2014; Chervenkov and Slavov, 2020a; Croitoru et al., 2012; Lakatos et al., 2013, and many others) or global (Sillmann et al., 2013) long-term climate changes.

The Mann-Kendall (MK) test is a non-parametric procedure, especially suitable for non-normally distributed data, data containing outliers, and nonlinear trends (Birsan et al., 2014). Subsequently, it is used as practically standard tool for estimation of the statistical significance of trends in time series of climate variables (see references above).

The estimation of the magnitude of the trend is performed with the TheilSen estimator (TSE), which is also a non-parametric procedure, using a linear model to estimate the slope of the trend (Croitoru et al., 2012). It is increasingly applied in many geophysical branches, including climatology, as superior alternative of the ordinary least squares (see Chervenkov and Slavov, 2019b, and references therein). The MK test as well as the TSE were applied for each of the considered variables, on the time series of 58 annual values (from 1961 to 2018) and for all 301×321 grid cells individually. The results are presented in Fig. 6 .

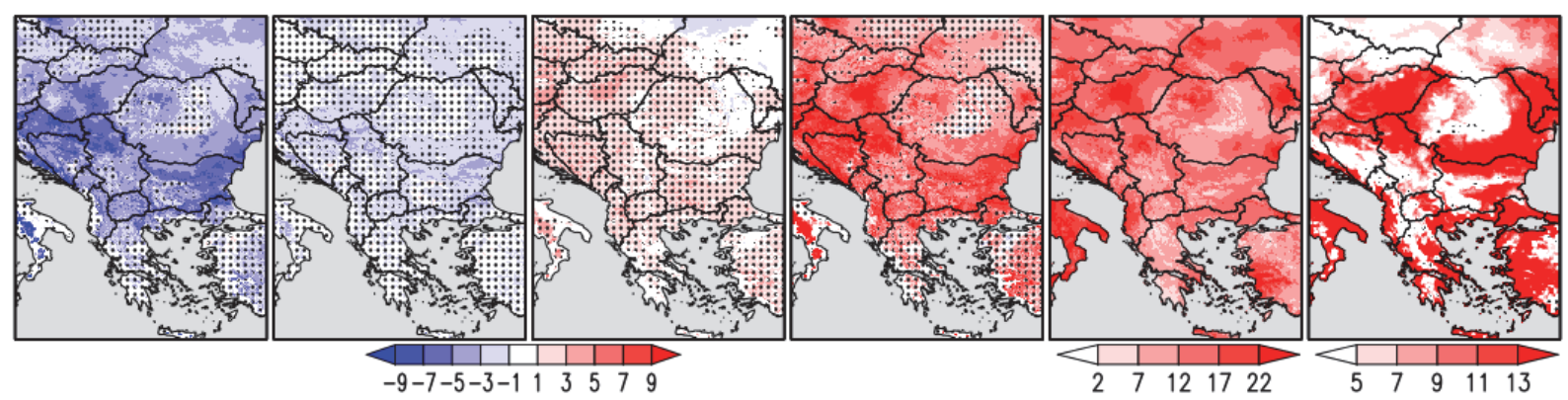

Fig. 6. Trend magnitude for DOYB, DOYM, DOYC, GSL, AAT, and BEDD in the first, second, third, fourth, fifth, and sixth column, correspondingly The units for $D O Y B$, $D O Y M, D O Y C$, and $G S L$ are days/10 years; for $A A T$ is ${ }^{\circ} \mathrm{D} / \mathrm{year}$, and for $B E D D$ is ${ }^{\circ} \mathrm{D} / 10$ years. Stippling indicates grid points with changes that are not significant at the $5 \%$ significance level.

Many conclusions could be drawn from Fig. 6. The first and foremost conclusion is the notable increasing trend for GSL, AAT, and BEDD. This trend 
dominates practically over the whole domain and is statistically significant at the $5 \%$ significance level over the low-elevated regions which, generally, are the biggest importance for the agriculture. As it is expected, mountains have the weakest trend for $G S L, A A T$, and $B E D D$ without statistical significance. The vertical gradient in the spatial pattern of the trend is most notable for the $B E D D$ index. $D O Y B$ demonstrates clear decreasing trend which, with values typically between -5 days $/ 10$ years and -1 days/10 years, is statistically significant over the flat regions. This result, in particular, confirms the finding in Lakatos et al. (2013b), where it is revealed that the DOYB shows significant change over the low-elevated areas of the Carpathian Region in 1961-2010 period. The areas experiencing decreasing trend of DOYM and increasing trend of DOYC are spatially dominating. These trends, however, are relatively week and, generally, statistically not significant.

As noted in Birsan et al. (2014) in their study of the thermal extremes over the Carpathian Region, the signal of the significant trends of the considered parameters is spatially consistent as there are no areas of mixed trends within the study domain.

\section{Conclusion}

The present study provides an overview of the spatial patterns in very high resolution and the long-term temporal evolution on annual basis of the selected AM indices over SE Europe in the period 1961-2018. Generally, it confirms the essential impact of the ongoing climate change on the agriculture and forestry in the region. As noted in Section 2.2., however, the application of the selected indices cannot be limited to their agricultural implementations only, hence they could be treated as measures of the cumulative thermal conditions during the warm half of the year.

Consistently with the long-term changes of the mean temperatures over the domain, documented in the most recent papers, the present study reveals strong evidences for the role of the regional climate warming on the considered indices. The GSL, $A A T$, and $B E D D$ indices experienced essential increase which dominates spatially over the low-elevated areas of the domain and is statistically significant at the 5\% significance level. Key message is also the revealed asymmetry in the increase of the most relevant index, the GSL: its total lengthening is linked more (more than $70 \%$ as relative share over the bigger part of the domain) to the shifting to earlier date of the start, rather than to later cessation. Our proposal is to use the middle day of the GSL, DOYM, as indicator for such long-term shifts appears also novel in this regard. Our computations show that $D O Y M$ is shifted to earlier dates practically over the whole domain, but this shift is statistically not significant over its bigger part. 
The estimated changes of the AM indices in the near past and recent climate could be also prerequisite for deep ecological and economical consequences. Longer growing seasons, as well as bigger $A A T$ and $B E D D$, may allow for a greater diversity of crops (including those with long maturation periods), and the potential for multiple harvests on the same land. Conversely, both irrigation needs and the risk from invasive species, pests, and pathogens may increase (Harding et al., 2015).

The study could be extended and continued in many directions. The logical next step is to accomplish the work assessing the future changes and trends based on climate simulations. Hence the temperatures in all CMIP5 scenarios are projected to rise further, it is reasonable to expect additional increase of these indicators. Our preliminary computations with the regional climate model RegCM confirm this assumption. The study could also be extended backwards in time, as far as possible, in order to capture more general and robust trends. However, as for many other efforts in the regional climatology, the necessary prerequisite for such task is the (free) availability of reliable data with proper spatial coverage and spatio-temporal resolution.

The data sets with the AM indices, as well as the trend measures (p-value and trend line slope) are in standard form (GrADS binary/descriptor files) and could be supplied from the corresponding author upon request.

Acknowledgments: This work is based on the UERRA project (EU FP7 Collaborative Project, Grant agreement 607193). Hence this study entirely exploits free available data and software, the authors would like to express their deep gratitude to the organizations and institutions (UERRA project, CARPATCLIM, MPI-M, UNI-DATA, Copernicus Data Store), which provides free of charge software and data. Without their innovative data services and tools this work would be not possible. Personal thanks to I. Tsonevsky from ECMWF for the cooperation. The authors also thank the anonymous reviewer for the useful comments on first version of this manuscript.

\section{References}

Alexandrov, V., Schneider, M., Koleva, E., and Moisselin, J.-M., 2004: Climate variability and change in Bulgaria during the 20th century. Theor. Appl. Climatol. 79, 133-149. https://doi.org/10.1007/s00704-004-0073-4

Bartholy, J. and Pongrácz, R., 2006: Comparing tendencies of some temperature related extreme indices on globaland regional scales. Időjárás 110, 35-48.

Bazile, E., Abida, R., Verelle, A., Le Moigne, P., and Szczypta, C., 2017: MESCAN-SURFEX surface analysis, deliverable D2.8 of the UERRA project. http://www.uerra.eu/publications/deliverable-reports.html

Belda, M., Skalák, P., Farda, A., Halenka, T., Déqué,M., Csima, G., Bartholy, J., Torma, C., Boroneant, C, Caian, M., Spiridonov,V. 2015: CECILIA Regional Climate Simulations for Future Climate: Analysis of Climate Change Signal. Adv. Meteorology 2015, Article ID 354727, 13 pages, $2015 \mathrm{https}: / /$ doi.org/10.1155/2015/354727

Birsan, M.-V., Dumitrescu, A.,Micu, D.M., and Cheval, S., 2014: Changes in annual temperature extremes in the Carpathians since AD 1961. Nat. Hazards 74, 1899-1910. https://doi.org/10.1007/s11069-014-1290-5 
Chervenkov, H., Slavov, K., and Ivanov, V., 2019: STARDEX and ETCCDI Climate Indices Based on E-OBS and CARPATCLIM; Part One: General Description. In (Eds. G. Nikolov et al.): NMA 2018, LNCS 11189, 360-367. https://doi.org/10.1007/978-3-030-10692-840

Chervenkov, H. and Slavov, K., 2019a: STARDEX and ETCCDI Climate Indices Based on E-OBS and CARPATCLIM; Part Two: ClimData in Use. In (Eds. G. Nikolov et al.) NMA 2018, LNCS 11189, 368-374. https://doi.org/10.1007/978-3-030-10692-841

Chervenkov, H. and Slavov, K., 2019b: Theil-Sen Estimator vs. Ordinary Least Squares - Trend Analysis for Selected ETCCDI Climate Indices. C. R. Acad. Bulg. Sci. 72, 47-54. https://doi.org/10.7546/CRABS.2019.01.06

Chervenkov, H. and Slavov, K., 2020: Historical Climate Assessment of Temperature-based ETCCDI Climate Indices Derived from CMIP5 Simulations, Compt. rend. Acad. bulg. Sci. 73, 784-790. https://doi.org/10.7546/CRABS.2020.06.05

Chervenkov, H. and Slavov, K., 2021: Geo-statistical Comparison of UERRA MESCAN-SURFEX Daily Temperatures Against Independent Data Sets. Időjárás 125, 123-135. https://doi.org/10.28974/idojaras.2021.1.6

Cheval, S., Birsan, M.-V., and Dumitrescu, A., 2014: Climate variability in the Carpathian Mountains Region over 1961-2010. Glob. Planetary Change 118, 85-96.

https://doi.org/10.1016/j.gloplacha.2014.04.005

Croitoru, A-E., Holobaca I-H., Lazar, C., Moldovan, F., and Imbroane, A., 2012 Air temperature trend and the impact on winter wheat phenology in Romania. Climatic Change 111, 393-410. https://doi.org/10.1007/s10584-011-0133-6

van Engelen, A., Klein Tank, A., van der Schrier, G., and Klok, L., 2008: European Climate Assessment \& Dataset (ECA\&D), Report 2008, "Towards an operational system for assessing observed changes in climate extremes". KNMI, De Bilt, The Netherlands.

Gadzhev, G., Georgieva, I., Ganev, K., Ivanov, V., Miloshev, N., Chervenkov, H., and Syrakov, D., 2018: Climate Applications in a Virtual Research Environment Platform. Scalab. Computi.: Practice Exper. 19, 107-118. https://doi.org/10.12694/scpe.v19i2.134

Gladstones, J.: 1992: Viticulture and Environment. Winetitles, Adelaide.

Harding, A.E., Rivington, M., Mineter M.J., and Tett S.F.B., 2015: Agro-meteorological indices and climate model uncertainty over the UK. Climatic Change 128, 113-126 https://doi.org/10.1007/s10584-014-1296-8

Janković, A., Podraščanin, Z., and Djurdjevic, V., 2019: Future climate change impacts on residential heating and cooling degree days in Serbia. Idöjárás 123,351-370.

Lakatos, M., Bihari, Z., Szentimrey, T., Szalai, S., and the CARPATCLIM project Team, 2013a: Climate of the Carpathian Region - summary of the CarpatClim project, 3th EMS Annual Meeting \& 11th European Conference on Applications of Meteorology (ECAM) - 09-13 September 2013, Reading, United Kingdom.

http://presentations.copernicus.org/EMS2013-501presentation.pdf

Lakatos, M., Szentimrey, T., Bihari, Z., and Szalai, S., 2013b: Investigation of climate extremes in the Carpathian region on harmonized data, Int. Scient. Conf. on Environmental Changes and Adaptation Strategies, Sep., 2013 Temperature thresholds and crop production: a review.

Lindner, M., Maroschek, M., Netherer, S., Kremer, A., Barbati, A., Garcia-Gonzalo, J., Seidl, R., Delzon, S., Corona, P., Kolström, M., Lexer, M. J. and Marchetti, M., 2010: Climate change impacts, adaptive capacity, and vulnerability of European forest ecosystems. Forest Ecol. Manage. 259, 698-709. https://doi.org/10.1016/j.foreco.2009.09.023

Luo, Q., 2011: Temperature thresholds and crop production: a review. Climatic Change 109, 583-598. https://doi.org/10.1007/s10584-011-0028-6

Malcheva, K., Chervenkov, H., and Marinova, T., 2016: Winter Severity Assessment on the Basis of Measured and Reanalysis data. In: 16th International Multidisciplinary Scientific GeoConference SGEM 2016. SGEM, 719-726.

Mesterházy, I., Mészáros, R., Pongrácz, R., Bodor, P., and Ladányi, M., 2018: The analysis of climatic indicators using different growing season calculation methods - an application to grapevine grown in Hungary, Idöjárás 122, 217-235. https://doi.org/10.28974/idojaras.2018.3.1 
Mihai, G, Bîrsan, M.-V. Dumitrescu, A., Alexandru, A., Mirancea, I., Ivanov, P., Stuparu, E., Teodosiu, M., Daia, M.,., 2018: Adaptive genetic potential of European silver fir in Romania in the context of climate change. Ann. For. Res. Vol. 61, No. 1, 95-108. https://doi.org/10.15287/afr.2018.1021

Mihai, G., et al. ,2020: Impact of Climate Change and Adaptive Genetic Potential of Norway Spruce at the South-eastern Range of Species Distribution. Agr. Forest Meteorol., 291, 108040. https://doi.org/10.1016/j.agrformet.2020.108040

Pieczka, J., Bartholy, J., Pongrácz R., and André, K.S., 2019: Validation of RegCM regional and HadGEM global climate models using mean and extreme climatic variables. Idöjárás 123, 409-433. https://doi.org/1.0.28974/idojaras.2019.4.1

Pongrácz, R., Bartholy, J., Gelybó, G., and Szabó, P., 2009a: Detected and Expected Trends of Extreme Climate Indices for the Carpathian Basin. In: (Eds. Střelcová K. et al.) Bioclimatology and Natural Hazards. Springer, Dordrecht, https://doi.org/10.1007/978-1-4020-8876-6_2

Pongrácz, R., Bartholy, J., Gelybó, G., and Szabó, P., 2009b: A comparison of the observed trends and simulated changes in extreme climate indices in the Carpathian Basin by the end of this century. Int. J. Global Warming, 1, 336-355. https://doi.org/10.1504/IJGW.2009.027097

Ridal, M., Schimanke, S., and Hopsch, S., 2018: Documentation of the RRA system: UERRA, deliverable D322 Lot1.1.1.2 in the scope of the Copernicus service C3S 322 Lot1, available via Copernicus.

Seemann, J., Chirkov, Y.I., Lomas, J., and Primault, B., 1979: Agrometeorology, SpringerVerlag.Berlin Heidelberg New York. https://doi.org/10.1 007/978-3-642-67288-0

Sillmann, J., V.V. Kharin, X. Zhang, F.W. Zwiers, and D. Bronaugh, 2013: Climate extremes indices in the CMIP5 multimodel ensemble: Part 1. Model evaluation in the present climate. J. Geophys. Res. Atmos., 118, 1716-1733. https://doi.org/10.1002/jgrd.50203

Soci, C., Bazile, E., Besson, F., and Landelius, T., 2016: High-resolution precipitation re-analysis system for climatological purposes. Tellus A: 68, https://doi.org/10.3402/tellusa.v68.29879

Spinoni, J., Szalai, S., Szentimrey, T., Lakatos, M., Bihari, Z., Nagy, A., Németh, Á., Kovács, T., Mihic, D., Dacic, M., Petrovic, P., Kržič, A., Hiebl, J., Auer, I., Milkovic, J., Štepánek, P., Zahradnícek, P., Kilar, P., Limanowka, D., Pyrc, R., Cheval, S., Birsan, M. V., Dumitrescu, A., Deak, G., Matei, M., Antolovic, I., Nejedlik, P., Štastný, P., Kajaba, P., Bochnicek, O., Galo, D., Mikulová, K., Nabyvanets, Y., Skrynyk, O., Krakovska, S., Gnatiuk, N., Tolasz, R., Antofie, T. and Vogt, J., 2015: Climate of the Carpathian Region in the period 1961-2010: climatologies and trends of 10 variables. Int. J. Climatol. 35, 1322-1341. https://doi.org/10.1002/joc.4059

Spiridonov, V. and Valcheva, R., 2019: A new index for climate change evaluation. An example with the ALADIN and RegCM regional models for the Balkans and the Apennines. Idójárás 123, 551-576, https://doi.org/10.28974/idojaras.2019.4.9

Szyga-Pluta, K. and Tomczyk, A.M., 2019: Anomalies in the length of the growing season in Poland in the period 1966-2015. Idöjárás 123, 391-408. https://doi.org/10.28974/idojaras.2019.3.8

Unden, P., 2018: UERRA: Final Report, Project No.: 607193, Period number: 3rd Ref: 607193 UERRA Final Report-13 20180319112103 CET.pdf

Zhang, X., Alexander, L., Hegerl, G.C., Jones, P., Tank, A.K., Peterson, T.C., Trewin, B., and Zwiers, $F . W$., 2011: Indices for monitoring changes in extremes based on daily temperature and precipitation data. WIREs. Climate Change 2, 851-870. https://doi.org/10.1002/wcc.147 